Audiology

Neurotology
Audiol Neurotol 2016;21:22-29

DOI: $10.1159 / 000441833$
Received: April 23, 2015

Accepted after revision: October 19, 2015

Published online: January 21, 2016

\title{
The Sustained-Exposure Dexamethasone Formulation OTO-104 Offers Effective Protection against Cisplatin-Induced Hearing Loss
}

\author{
Rayne Fernandez Anne Harrop-Jones Xiaobo Wang Luis Dellamary \\ Carl LeBel Fabrice Piu
}

Otonomy Inc., San Diego, Calif., USA

\author{
Key Words \\ Ototoxicity · Cisplatin · Sustained exposure · \\ Dexamethasone
}

\begin{abstract}
The otoprotective effects of OTO-104 were investigated following both acute and chronic administration of cisplatin. The acute administration of cisplatin to guinea pigs resulted in profound hearing loss (70-80 dB SPL) across all frequencies tested. A single intratympanic injection of 6\% OTO-104, but not of lower doses, almost completely protected against cisplatin ototoxicity. In contrast, a dexamethasone solution administered under the same experimental conditions offered no otoprotection. OTO-104 was also very effective in protecting against the progressive hearing loss observed with the chronic administration of cisplatin ( 3 injections at a weekly interval). The otoprotection was found to be dependent upon the activation of dexamethasone-dependent classical nuclear receptor pathways.
\end{abstract}

(C) 2016 The Author(s)

Published by S. Karger AG, Basel

Rayne Fernandez and Anne Harrop-Jones contributed equally to this work.
(C) 2016 The Author(s)

Published by S. Karger AG, Basel $1420-3030 / 16 / 0211-0022 \$ 39.50 / 0$

This article is licensed under the Creative Commons AttributionNonCommercial-NoDerivatives 4.0 International License (CC BYNC-ND) (http://www.karger.com/Services/OpenAccessLicense). Usage and distribution for commercial purposes as well as any distribution of modified material requires written permission.

\section{Introduction}

Cisplatin is a potent chemotherapeutic agent that is widely used to treat a variety of cancers. However, its administration is commonly associated with severe side effects, including nephrotoxicity, peripheral neuropathy and ototoxicity [Coradini et al., 2007]. Cisplatin-induced otoxicity, one of the dose-limiting side effects, manifests itself as sensorineural hearing loss and tinnitus [Saito and Aran, 1994; Dille et al., 2010]. The hearing loss is progressive, bilateral and irreversible, and preferentially affects high frequencies.

The ototoxicity of cisplatin is characterized essentially by damage to the cochlea [Nakai et al., 1982]. The primary site of cochlear toxicity is oriented toward the outer hair cells, but other affected structures include the inner hair cells, spiral ganglion and stria vascularis. The effects are dose dependent and target the lower turns of the cochlea, consistent with the predominant high-frequency hearing loss. At the cellular level, cisplatin induces a complex network of events, including the generation of reactive oxygen species, the activation of inflammatory cytokines and the induction of stress signaling pathways [Boulikas and Vougiouka, 2003; Rybak et al., 2007]. These events eventually lead to cell death via the induction of apoptosis [Boulikas and Vougiouka, 2003]. 
Dexamethasone has been shown to protect auditory hair cells against inflammatory cytokines by activating cell survival pathways [Haake et al., 2009]. In addition, dexamethasone can suppress drug toxicity imparted to free radicals by upregulating antioxidant enzyme activity [Himeno et al., 2002; Paksoy et al., 2011]. Dexamethasone thus appears to be a good candidate for otoprotection. However, there is surprisingly little available information regarding the prevention of cisplatin ototoxicity by dexamethasone. Daldal et al. [2007] suggested that a single intratympanic injection of dexamethasone solution administered immediately prior to cisplatin treatment had an otoprotective effect in rats. Repeated intratympanic injections of dexamethasone (daily for 5 days) provided significant otoprotection against cisplatin when initially administered at the time of cisplatin treatment [Hill et al., 2008]. Murphy and Daniel [2011] have shown that in guinea pigs, intratympanic dexamethasone given the day prior and on the day of cisplatin treatment yielded a nonsignificant trend of protection against ototoxicity. Taken altogether, these studies suggest that an intratympanic injection of a dexamethasone solution protected against cisplatin ototoxicity only when administered concomitantly with cisplatin.

Reports to date are consistent with the short residence time of dexamethasone in the inner ear perilymphatic compartment when administered as a solution intratympanically. For instance, a dexamethasone solution is cleared rapidly from the middle ear down the Eustachian tube, with drug levels in the perilymph lasting for about $12 \mathrm{~h}$ in guinea pigs [Wang et al., 2009, 2011a, b]. In the clinic, inconsistent clinical responses are commonly observed due to variable and limited exposure with aqueous solutions [Bird et al., 2007, 2011]. Most likely, better clinical efficacy can be achieved by maintaining therapeutic drug levels for prolonged periods of time.

Sustained drug delivery to local compartments can be accomplished by ensuring the slow release of the therapeutic agent over time. Here, an evaluation of OTO-104 (poloxamer hydrogel containing dexamethasone) was conducted to investigate whether a single intratympanic injection could alleviate hearing loss in guinea pigs exposed to the ototoxic agent cisplatin. Previous studies have demonstrated that a single intratympanic injection of OTO-104 facilitates the presence of dexamethasone at therapeutic levels in the inner ear compartment for weeks to months in guinea pigs and sheep [Wang et al., 2009; Piu et al., 2011]. Recent results from a clinical study in patients with Ménière's disease have concluded that the intratympanic injection of OTO-104 was safe and well tolerated in this study population [Lambert et al., 2012].

\section{Materials and Methods}

\section{Chemicals}

Dexamethasone, dexamethasone sodium phosphate (DSP) and poloxamer 407 NF were purchased from Spectrum Chemicals. Cisplatin and mifepristone were obtained from Sigma Aldrich. Acepromazine, ketamine and xylazine were from MWI Veterinary. OTO-104 consisted of a sterile suspension containing dexamethasone in $16 \%$ poloxamer 407 prepared as previously described [Piu et al., 2011]. Briefly, a 16\% w/w solution of poloxamer 407 was prepared by slowly adding it to a cold buffered solution (10 mM PBS, pH 7.4). Heat-sterilized micronized dexamethasone was suspended with an appropriate amount of sterile poloxamer 407 solution using aseptic techniques. The samples were kept under refrigeration and resuspended before administration. The DSP solution was prepared by dissolving DSP in a buffer solution (10 $\mathrm{mM}$ PBS, $\mathrm{pH}$ 7.4) and subsequent sterile filtration as previously described [Wang et al., 2011b]. Mifepristone was formulated as a $6.0 \%$ sterile suspension in $16 \%$ poloxamer 407 .

\section{Animal Studies}

All animal studies were conducted in accordance with the policies and recommendations of the US Department of Agriculture and the National Institute of Health guidelines for the handling and use of laboratory animals, and received approval from the Institutional Animal Care and Use Committee of Otonomy Inc. Female guinea pigs (Hartley; Charles River; $\mathrm{n}=6$ per group) weighing 200-300 g of approximately 6-8 weeks of age served as subjects for the experiments. The sample size of this experiment was not based on power calculation. This study was conducted as an exploratory study. The number of subjects per group was chosen based on prior experience ( $n=6$ appeared sufficient to detect differences between treatment regimen), operational limitations (such as noise exposure) and concerns from Otonomy's Institutional Animal Care and Use Committee to limit the number of animals on study. Prior to any procedure, the animals were anesthetized using a combination of xylazine $(10 \mathrm{mg} / \mathrm{kg})$, ketamine $(40$ $\mathrm{mg} / \mathrm{kg})$ and acepromazine $(0.75 \mathrm{mg} / \mathrm{kg})$ for up to $1 \mathrm{~h}$ via the intramuscular route.

\section{Intratympanic Injection}

All animals were injected bilaterally. Each animal was positioned so that the head was tilted at an angle to favor injection towards the round window niche. Briefly, under visualization with an operating microscope, $50 \mu \mathrm{l}$ of the formulation was injected using a 27- or 30-gauge needle through the tympanic membrane into the superior posterior quadrant behind which the round window niche is located. To ensure adequate exposure to the round window, the animals were maintained in that position for $30 \mathrm{~min}$. Subsequently, the second ear was dosed under the same conditions. Within a same treatment group, all animals received the same formulation lots. During the procedure and until recovery, the animals were placed on a temperature controlled $\left(37-39^{\circ} \mathrm{C}\right)$ heating pad. After consciousness was regained, the animals were returned to the vivarium.

\section{Cisplatin Ototoxicity}

The lower right quadrant of the abdomen of the anesthetized guinea pigs was shaved (approx. 1 inch $^{2}$ ) and swabbed with alcohol. The animals were placed in a supine position and the hind legs 


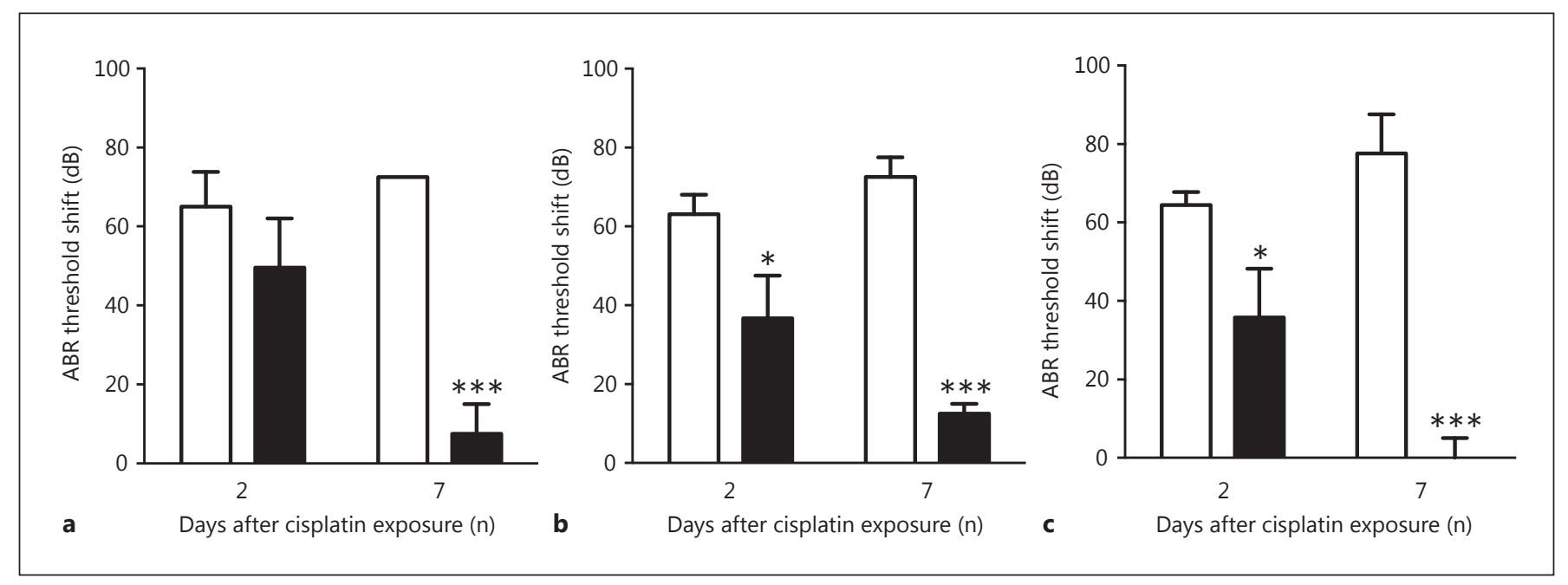

Fig. 1. Protection of OTO-104 against acute exposure to cisplatin is progressive. Guinea pigs $(n=6)$ received a single bilateral intratympanic injection of poloxamer vehicle (white bars) or 6.0\% OTO-104 (black bars); 1 day later, the animals were given a single administration of cisplatin $(12 \mathrm{mg} / \mathrm{kg})$. Frequencies: $4 \mathrm{kHz}(\mathbf{a}), 8 \mathrm{kHz}(\mathbf{b})$ and $16 \mathrm{kHz}(\mathbf{c})$. Auditory function (mean + SEM) was assessed at the indicated times. ${ }^{*} \mathrm{p}<0.05{ }^{* * *} \mathrm{p}<0.001$.

are lifted at a 40-degree angle in order to move the abdominal organs towards the diaphragm. A 1-inch 23-gauge needle or larger was inserted into the abdominal cavity, directed towards the animal's head, at a 15- to 20-degree angle and inserted approximately $5 \mathrm{~mm}$. Aspiration was attempted to ensure that the abdominal viscus had not been penetrated, and cisplatin was slowly injected for a duration of $30 \mathrm{~min}$ (approximately $0.1 \mathrm{ml}$ per every 1-2 min). The animals were allowed to recover on a warming pad and returned to clean cages when conscious. In the acute cisplatin ototoxicity model, the guinea pigs received a single injection of cisplatin $(1 \mathrm{mg} / \mathrm{ml})$ to ensure delivery of $12 \mathrm{mg} / \mathrm{kg}$ cisplatin. In the chronic model, the guinea pigs receive weekly injections of $4 \mathrm{mg} /$ $\mathrm{kg}$ cisplatin for 3 weeks.

\section{Auditory Brainstem Response Assessment}

During the procedure, additional anesthetic (xylazine and ketamine) was administered if needed to maintain a depth of anesthesia sufficient to insure immobilization and relaxation. Auditory brainstem responses (ABRs) were recorded in an electrically and acoustically shielded chamber in each ear sequentially. Needle electrodes were placed at the vertex (active) and immediately below the pinna of the test ear (reference) and contralateral ear (ground). Tucker-Davis Technologies (TDT) System III hardware and SigGen/BioSig software (TDT) were used to present the stimulus and record the ABR responses. Tones were delivered through a Tucker-Davis open-field ES1 driver placed $5 \mathrm{~cm}$ above the animal's ear. Acoustic calibration was performed with TDT software (SigCal), and thresholds were expressed as decibel SPL in conditions identical to those of threshold recordings in animals. Stimulus presentations (15-ms tone bursts, with 1 -ms rise/fall times) were presented 10 per s. Up to 512 responses were averaged for each stimulus level. Responses were collected for stimulus levels in $5-\mathrm{dB}$ decrement steps at 3 frequencies: 4,8 and $16 \mathrm{kHz}$. Thresholds were interpolated between the lowest stimulus level where a response was observed and $5 \mathrm{~dB}$ lower where no response was observed. The threshold was then reported as the mean value between these two stimulus conditions.

\section{Data Analysis}

Auditory function was monitored at the indicated times across 3 frequencies $(4,8$ and $16 \mathrm{kHz})$. Results are presented as mean + standard error to the mean (SEM). The use of SEM is justified in studies where the intent is to compare effects across treatment groups. Specifically, SEMs represent the spread of the mean of the sample (the precision of the mean). Since the group sizes were identical within experiments, the use of SEM was deemed appropriate. The sample size was not powered to detect a prespecified difference in ABR between experimental and control arms. However, a difference of $20 \mathrm{~dB}$ was detectable in that study and clinically meaningful. Statistical analyses included a one-way ANOVA followed by Student's t test.

\section{Results}

OTO-104, a sustained-exposure hydrogel formulation of dexamethasone, was investigated in an acute cisplatin ototoxicity paradigm (fig. 1). Guinea pigs received OTO$104(6.0 \%)$ one day prior to a single injection of cisplatin (12 mg/kg). The OTO-104 dose was selected because it previously demonstrated efficacy in an acute acoustic trauma paradigm (F.P., unpubl. data). Vehicle (poloxamer)-treated animals exhibited a drastic shift in hearing threshold, ranging from $63.1 \pm 4.9$ to $65.0 \pm 8.8 \mathrm{~dB}$ by 


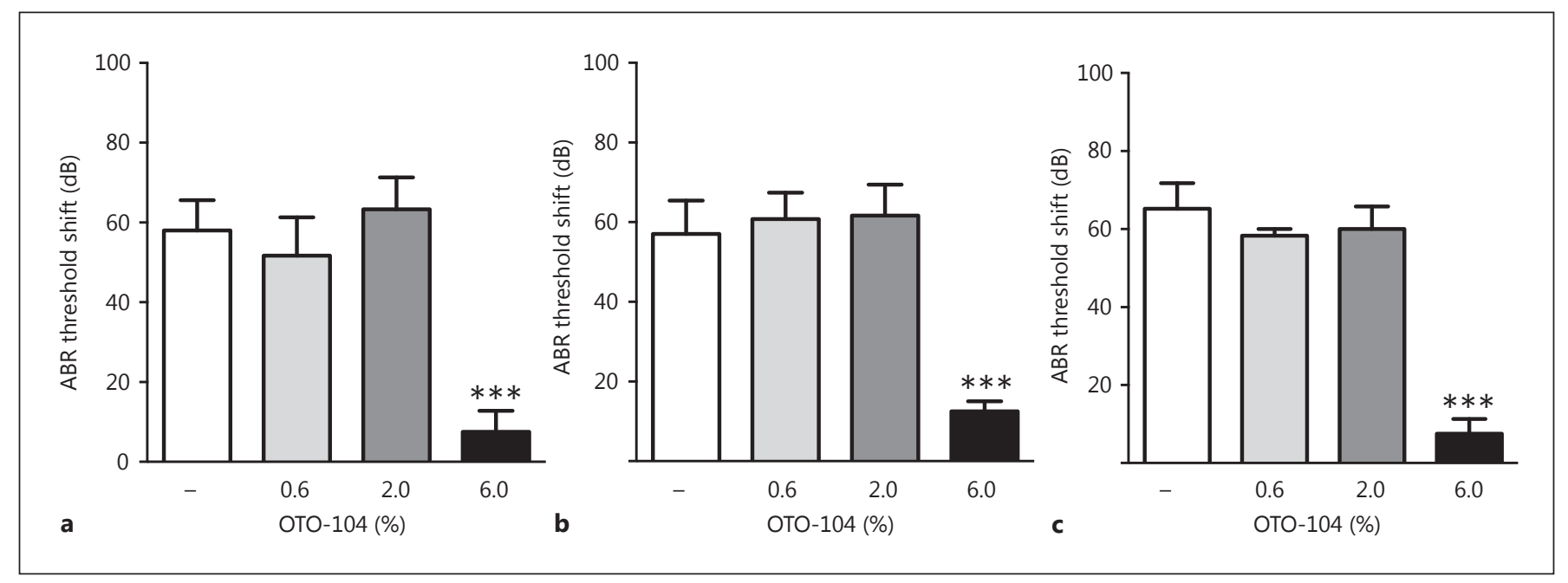

Fig. 2. High doses of OTO-104 protect against acute exposure to cisplatin. Guinea pigs $(\mathrm{n}=6)$ received a single bilateral intratympanic injection of various doses of OTO-104: poloxamer vehicle (white bars), 0.6\% OTO-104 (light grey bars), 2.0\% OTO-104 (dark grey bars) or 6.0\% OTO-104 (black bars); 1 day later, the animals were given a single administration of cisplatin $(12 \mathrm{mg} / \mathrm{kg})$. Frequencies: $4 \mathrm{kHz}(\mathbf{a}), 8 \mathrm{kHz}(\mathbf{b})$ and $16 \mathrm{kHz}(\mathbf{c})$. Auditory function (mean + SEM) was assessed at day 7 after cisplatin treatment. ${ }^{* * *} \mathrm{p}<0.001$.

day 2, worsening by day 7 from $72.5 \pm 5.0$ to $77.5 \pm 10.0$ $\mathrm{dB}$ across all tested frequencies $(4,8$ and $16 \mathrm{kHz})$. In contrast, the administration of OTO-104 almost completely reversed the hearing loss induced by cisplatin, to a low threshold shift varying between $12.5 \pm 2.5$ and $0.0 \pm 5.0$ $\mathrm{dB}$ from baseline by day 7 , across frequencies $(\mathrm{p}<0.001$ at all 3 frequencies).

In order to understand dose relationship, varying concentrations of OTO-104, ranging from 0.6 to $6.0 \%$, were evaluated (fig. 2). These doses were previously shown to provide therapeutic drug levels within the inner ear from days to weeks in animals [Piu et al., 2011]. Interestingly, a dose of $6.0 \%$ OTO-104 was more effective than doses of 2.0 and $0.6 \%$ in affording protection against cisplatin-induced hearing loss. For instance, at the $16-\mathrm{kHz}$ frequency, the ABR threshold shift relative to baseline was $58.3 \pm 1.7$ $\mathrm{dB}$ for the $0.6 \%$ OTO-104 dose ( $\mathrm{p}=0.353), 60.2 \pm 5.8 \mathrm{~dB}$ with $2.0 \%$ OTO-104 $(\mathrm{p}=0.582)$ and $7.5 \pm 3.8 \mathrm{~dB}$ with $6 \%$ OTO-104 ( $\mathrm{p}<0.001$ ) compared to $65.2 \pm 6.6$ in vehicletreated animals. In addition, when the guinea pigs were treated with a $2.0 \%$ DSP solution, no significant differences ( $p=0.147$ ) between control (threshold shift of 56.3 $\pm 2.5 \mathrm{~dB}$ at $16 \mathrm{kHz}$ ) and treated (threshold shift of $42.5 \pm$ $7.9 \mathrm{~dB}$ at $16 \mathrm{kHz}$ ) animals were noted, indicating a lack of otoprotection by the steroid solution with limited middle ear residence time (fig. 3).

Otoprotection by a Sustained-Release

Dexamethasone Hydrogel
Next, the effects of the glucocorticoid and the mineralocorticoid antagonist mifepristone were evaluated (fig. 4). The guinea pigs that received mifepristone alone had a hearing deficit $(55.0 \pm 2.0 \mathrm{~dB}$ at $16 \mathrm{kHz}$ at day 7 , $\mathrm{p}=0.128$ ) following cisplatin administration that was comparable or worse than the poloxamer control group $(62.5 \pm 3.9 \mathrm{~dB}$ at $16 \mathrm{kHz}$ at day 7$)$. When mifepristone was coadministered, the otoprotective effect of OTO-104 was completely abolished: from $12.5 \pm 3.2 \mathrm{~dB}(\mathrm{p}<0.001)$ to $61.7 \pm 4.8 \mathrm{~dB}(\mathrm{p}=0.899)$ at $16 \mathrm{kHz}$ at day 7 , suggesting that the mechanism of action of OTO-104 is primarily dependent upon the activation of classical nuclear receptor pathways.

Finally, a model of chronically administered cisplatin was developed (fig. 5). The guinea pigs received 3 weekly administrations of cisplatin $(4 \mathrm{mg} / \mathrm{kg})$. Intratympanic administration of $6.0 \%$ OTO-104 was given once weekly prior each cisplatin treatment. The hearing loss observed following chronic administration of cisplatin was gradual, reaching a plateau after the last injection, and was more pronounced at higher frequencies. On day 23 , the hearing deficit was $27.5 \pm 5.2 \mathrm{~dB}$ at $4 \mathrm{kHz}$, $26.3 \pm 13.9 \mathrm{~dB}$ at $10 \mathrm{kHz}$ and $41.3 \pm 10.3 \mathrm{~dB}$ at $16 \mathrm{kHz}$. In contrast, the guinea pigs treated with OTO-104 exhibited a minimal hearing deficit of $10.0 \pm 3.5 \mathrm{~dB}$ at $4 \mathrm{kHz}(\mathrm{p}=0.022), 7.5 \pm 4.8$ at $10 \mathrm{kHz}(\mathrm{p}=0.247)$ and $11.3 \pm 7.3 \mathrm{~dB}$ at $16 \mathrm{kHz}(\mathrm{p}=0.041)$. It should be noted 


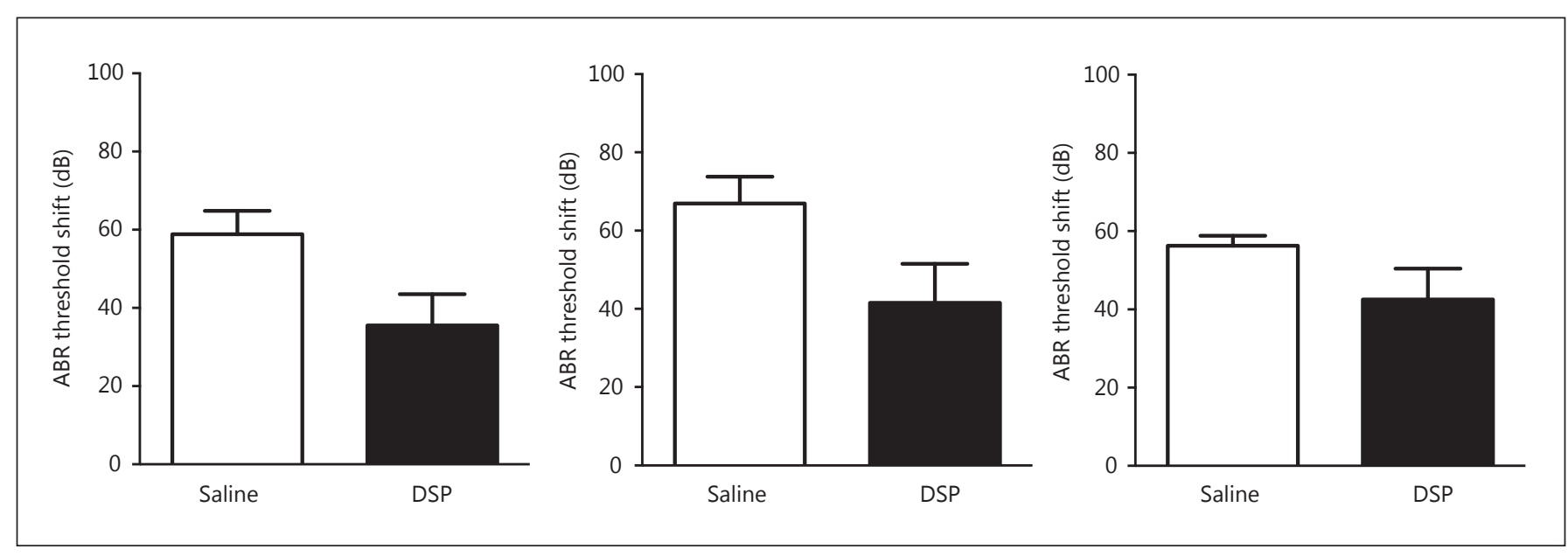

Fig. 3. DSP solution does not protect against acute exposure to cisplatin. Guinea pigs $(n=6)$ received a single bilateral intratympanic injection of either saline (white bars) or 2.0\% DSP solution (black bars); 1 day later, the animals were given a single administration of cisplatin $(12 \mathrm{mg} / \mathrm{kg})$. Frequencies: $4 \mathrm{kHz}(\mathbf{a}), 8 \mathrm{kHz}(\mathbf{b})$ and $16 \mathrm{kHz}$ (c). Auditory function (mean + SEM) was assessed at day 7 after cisplatin treatment.

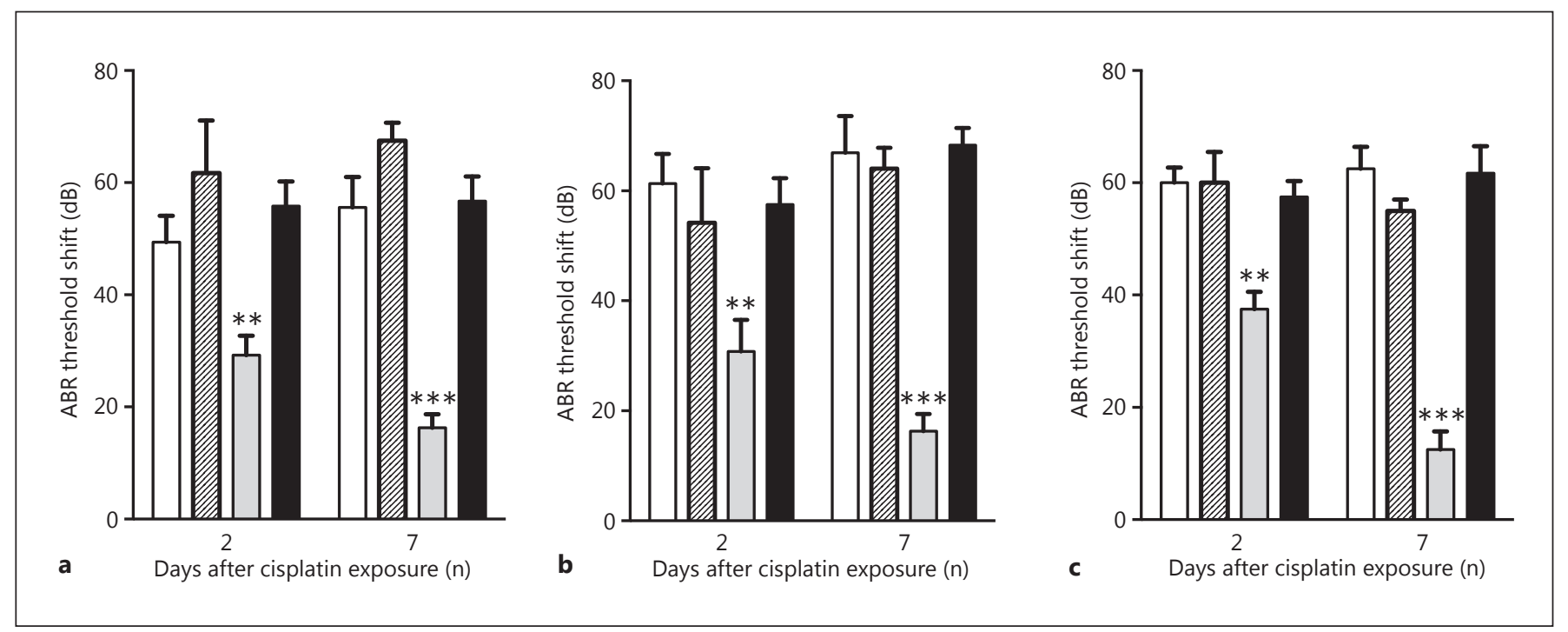

Fig. 4. Mifepristone antagonizes OTO-104 protection against acute cisplatin ototoxicity. Guinea pigs $(\mathrm{n}=6) \mathrm{re-}$ ceived a single bilateral intratympanic injection of either poloxamer vehicle (white bars), 6.0\% mifepristone (hatched light bars), 6.0\% OTO-104 (grey bars) or 6.0\% OTO-104 +6.0\% mifepristone (black bars); 1 day later, the animals were treated with cisplatin $(12 \mathrm{mg} / \mathrm{kg})$. Frequencies: $4 \mathrm{kHz}(\mathbf{a}), 8 \mathrm{kHz}(\mathbf{b})$ and $16 \mathrm{kHz}$ (c). Auditory function $\left(\right.$ mean + SEM) was assessed at the indicated times. ${ }^{* *} \mathrm{p}<0.01{ }^{* * *} \mathrm{p}<0.001$.

that the hearing threshold shift at day 23 in subjects treated with OTO-104 was not significantly different than the one observed at day 2 following the first cisplatin administration: at $16 \mathrm{kHz}$, the values were $8.3 \pm 3.1$ $\mathrm{dB}(\mathrm{p}=0.724), 4.2 \pm 2.0 \mathrm{~dB}(\mathrm{p}=0.547)$ and $8.3 \pm 4.6 \mathrm{~dB}$ $(\mathrm{p}=0.813)$, respectively.

\section{Discussion}

The findings presented herein demonstrate that the intratympanic administration of OTO-104, a sustainedexposure dexamethasone formulation, yields significant protection in paradigms of acute and chronic cisplatin- 


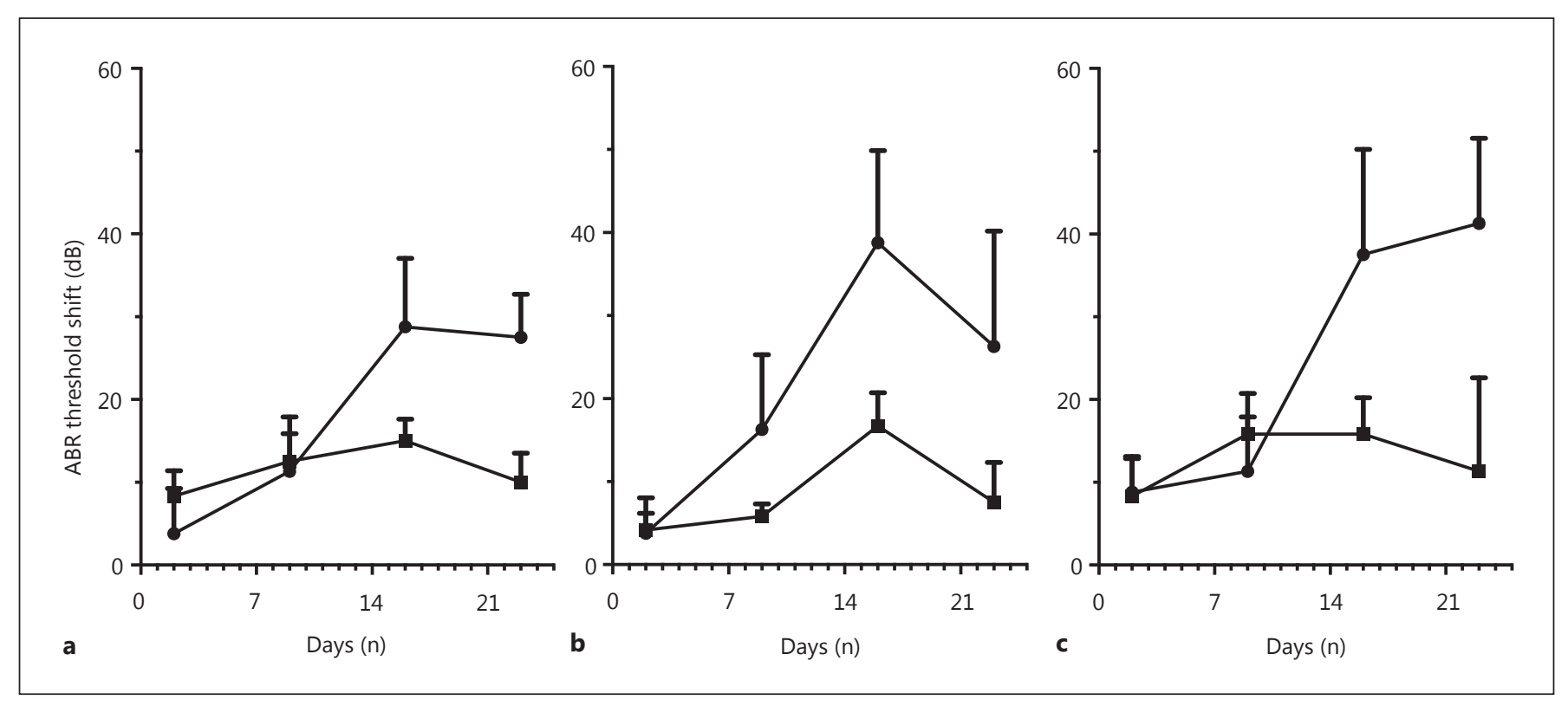

Fig. 5. OTO-104 protects against chronic exposure to cisplatin. Guinea pigs $(n=6)$ received 3 bilateral intratympanic injections at a 1-week interval of either poloxamer vehicle (circles) or 6.0\% OTO-104 (squares). Each of these injections was followed $30 \mathrm{~min}$ later by cisplatin administration $(4 \mathrm{mg} / \mathrm{kg})$. Frequencies: $4 \mathrm{kHz}(\mathbf{a}), 8 \mathrm{kHz}$ (b) and $16 \mathrm{kHz}(\mathbf{c})$. Auditory function (mean + SEM) was assessed at the indicated times.

induced hearing loss. This is in contrast to a dexamethasone solution which displayed no otoprotective benefits, under the experimental conditions.

Prior studies by several investigators suggested that intratympanic injection(s) of dexamethasone solution could be otoprotective against cisplatin, but only when given concomitantly with cisplatin [Daldal et al., 2007; Hill et al., 2008]. The studies described herein demonstrate that almost complete protection against cisplatininduced hearing loss was observed following a single injection of OTO-104 given 1 day prior to cisplatin exposure. A single intratympanic injection of OTO-104 facilitates the presence of dexamethasone in the inner ear compartment for days to weeks [Wang et al., 2009; Piu et al., 2011], maximizing the potential of the steroid to provide otoprotection against trauma over time. In contrast, when DSP solution was given intratympanically 1 day prior to cisplatin administration, no otoprotection was observed. Such results are consistent with the short residence time of dexamethasone in the inner ear compartment when administered as a solution intratympanically. In guinea pigs, a DSP solution is cleared rapidly, with drug levels in the perilymph lasting for about $12 \mathrm{~h}$ [Wang et al., 2009, 2011a, b]. Therefore, the therapeutic potential of dexamethasone is best achieved when the drug can re-

Otoprotection by a Sustained-Release

Dexamethasone Hydrogel main present in the inner ear compartment for extended periods of time.

The ability of mifepristone, a glucocorticoid and mineralocorticoid receptor antagonist, to antagonize the otoprotective effects of OTO-104 supports the notion that dexamethasone acts primarily by activating the glucocorticoid and mineralocorticoid nuclear receptors to alleviate cisplatin-induced hearing loss. These findings are consistent with published reports detecting the presence of glucocorticoid receptor in the cochlea, in particular the spiral ligament, stria vascularis and organ of Corti [ten Cate et al., 1993; Rarey and Curtis, 1996]. These otic compartments are the sites of action of cisplatin; ototoxicity induced by cisplatin primarily targets the cochlea, especially the outer hair cells, spiral ganglion cells and the marginal cells of the stria vascularis [Rybak, 2007]. The process is primarily apoptotic in nature [De Freitas et al., 2009], but an inflammatory response has also been noted [Kim et al., 2011]. The fact that OTO-104 provides almost complete protection against cisplatin ototoxicity implies that dexamethasone exhibits potent antiapoptotic properties in the inner ear. Dexamethasone has been shown to suppress apoptosis of auditory hair cells by activating the cell survival signaling pathways PI3K/Akt and NF- $\kappa \mathrm{B}$ [Haake et al., 2009; Van De Water et al., 2010]. Further- 
more, dexamethasone can inhibit drug toxicity due to the generation of free radicals by upregulating antioxidant enzyme activity [Himeno et al., 2002; Paksoy et al., 2011]. Coupled with its well-described anti-inflammatory properties, dexamethasone appears to constitute an effective therapeutic agent against ototoxic drugs.

Various agents have been evaluated for their otoprotective benefits against ototoxic drugs such as cisplatin [Abi-Hachem et al., 2010], ranging from antioxidants to kinase inhibitors, caspase inhibitors and growth factors. Local application, using minipumps, of the growth factors BDNF or FGF-2 did not prevent cisplatin-induced ototoxicity in guinea pigs [Wimmer et al., 2004]. Interestingly, the antiapoptotic MAPK inhibitor D-JNK1 (aka AM-111), a cell-permeable JNK peptide antagonist, did not protect against cisplatin-induced hearing loss, but instead potentiated the sensitivity of hair cells to cisplatin [Wang et al., 2004]. These findings were observed despite the fact that JNK activation is associated with cisplatin ototoxicity. The authors hypothesized that the JNK pathway may have a role in DNA repair and maintenance of damage sensory cells. Caspase inhibitors, targeting caspase 3 and 9, were quite effective in protecting against cisplatin-induced hearing loss in guinea pigs [Wang et al., 2004]. Antioxidants such as $\mathrm{N}$-acetyl cysteine, thiosulfate, D-Met and ebselen have all demonstrated significant otoprotection against cisplatin [Rybak et al., 1999; Korver et al., 2002; Choe et al., 2004; Berglin et al., 2011]. The degree of protection observed with OTO-104 in the studies described herein was similar to that reported for the different antioxidants and caspase inhibitors.

In clinical settings, cisplatin is usually administered as fixed treatment regimen cycles. The cycle period can vary from once a week to once a month, depending on the cancer modality. In many instances, the treatment regimen includes 3 successive administrations at 1-week intervals, with cumulative doses of $75-100 \mathrm{mg} / \mathrm{m}^{2}$. A similar paradigm was evaluated in the studies described herein. Guinea pigs received 3 once-weekly doses of cisplatin $(4 \mathrm{mg} /$ $\mathrm{kg}$ ), translating into a cumulative exposure to cisplatin of $80-95 \mathrm{mg} / \mathrm{m}^{2}$. This exposure is equivalent to that experienced by cancer patients undergoing cisplatin therapy. For instance, the recommended doses for testicular, ovarian and bladder cancers are 20, 75-100 and $50-70 \mathrm{mg} / \mathrm{m}^{2}$, respectively. The observed hearing loss following cisplatin treatment in guinea pigs was progressive, bilateral and more pronounced at higher frequencies, thus in essence comparable to the presentation noted in human patients [Coradini et al., 2007]. The intratympanic administration of OTO-104 at the initiation of each cycle completely pro- tected against cisplatin-induced ototoxicity. Hence, such a therapeutic approach could offer invaluable benefits to patients undergoing chemotherapy treatment, including maintaining the quality of life. The intratympanic administration of OTO-104 has been extensively studied both nonclinically in various species [Wang et al., 2009, 2011a, b; Piu et al., 2011] and clinically [Lambert et al., 2012]. It was not associated with adverse effects at doses that achieve sustained exposure both locally in the ear as well as systemically. In the otic compartment, an intratympanic injection of OTO-104 had no adverse effects on middle and inner ear integrity in animal studies. Systemic exposure appears negligible and thus no adverse effects have been observed clinically. Hence, the risks of fungal infections in immunologically suppressed patients after chemotherapy treated with a pretreatment intratympanic administration of a sustained-release steroid formulation are not anticipated.

Recently, Marshak et al. [2014] reported the findings of a prospective randomized controlled clinical trial evaluating the benefits of intratympanic dexamethasone in the prevention of cisplatin-induced hearing loss. Prior to each cisplatin treatment, 26 cancer patients received an intratympanic injection of dexamethasone solution (dose of 7-10 mg). As stated by the authors, the treatment had minimal effects toward the reduction of cisplatin ototoxicity despite the fact that the dexamethasone solution was administered shortly prior to the cisplatin session (about $150 \mathrm{~min}$ ). These findings illustrate the limitations of treatment with an intratympanic injection of a steroid solution since the solution gets cleared rapidly from the middle ear and provides limited temporal exposure to the inner ear. Hence, a sustained-exposure approach, such as OTO-104, represents a better strategy, providing higher and prolonged drug levels in the inner compartment.

In conclusion, the intratympanic administration of OTO-104, a sustained-exposure formulation of dexamethasone, provides significant protection against cisplatin ototoxicity. The therapeutic benefits were observed following acute and chronic administration of cisplatin.

\section{Disclosure Statement}

This research was funded exclusively by Otonomy Inc., and all authors are previous or current employees of the firm. The authors have received financial incentives from Otonomy Inc. in the form of stock options.
Fernandez/Harrop-Jones/Wang/ Dellamary/LeBel/Piu 


\section{References}

Abi-Hachem RN, Zine A, Van De Water TR: The injured cochlea as a target for inflammatory processes, initiation of cell death pathways and application of related otoprotective strategies. Recent Pat CNS Drug Discov 2010;5: 147-163.

-Berglin CE, Pierre PV, Bramer T, Edsman K, Ehrsson H, Eksborg S, Laurell G: Prevention of cisplatin-induced hearing loss by administration of a thiosulfate-containing gel to the middle ear in a guinea pig model. Cancer Chemother Pharmacol 2011;68:1547-1556.

Bird PA, Begg EJ, Zhang M, Keast AT, Murray DP, Balkany TJ: Intratympanic versus intravenous delivery of methylprednisolone to cochlear perilymph. Otol Neurotol 2007;28: 1124-1130.

Bird PA, Murray DP, Zhang M, Begg EJ: Intratympanic versus intravenous delivery of dexamethasone and dexamethasone sodium phosphate to cochlear perilymph. Otol Neurotol 2011;32:933-936.

-Boulikas T, Vougiouka M: Cisplatin and platinum drugs at the molecular level. Review. Oncol Rep 2003;10:1663-1682.

Choe WT, Chinosornvatana N, Chang KW: Prevention of cisplatin ototoxicity using transtympanic $\mathrm{N}$-acetylcysteine and lactate. Otol Neurotol 2004;25:910-915.

Coradini PP, Cigana L, Selistre SG, Rosito LS Brunetto AL: Ototoxicity from cisplatin therapy in childhood cancer. J Pediatr Hematol Oncol 2007;29:355-360.

Daldal A, Odabasi O, Serbetcioglu B: The protective effect of intratympanic dexamethasone on cisplatin-induced ototoxicity in guinea pigs. Otolaryngol Head Neck Surg 2007;137: 747-752.

De Freitas MR, Figueiredo AA, Brito GA, Leitao RF, Carvalho JV Jr, Gomes RM Jr, Ribeiro Rde A: The role of apoptosis in cisplatin-induced ototoxicity in rats. Braz J Otorhinolaryngol 2009;75:745-752.

Dille MF, Konrad-Martin D, Gallun F, Helt WJ, Gordon JS, Reavis KM, Bratt GW, Fausti SA: Tinnitus onset rates from chemotherapeutic agents and ototoxic antibiotics: results of a large prospective study. J Am Acad Audiol 2010;21:409-417.

- Haake SM, Dinh CT, Chen S, Eshraghi AA, Van De Water TR: Dexamethasone protects auditory hair cells against TNFa-initiated apoptosis via activation of PI3K/Akt and NFkB signaling. Hear Res 2009;255:22-32.
Hill GW, Morest DK, Parham K: Cisplatin-induced ototoxicity: effect of intratympanic dexamethasone injections. Otol Neurotol 2008;29:1005-1011.

Himeno C, Komeda M, Izumikawa M, Takemura K, Yagi M, Weiping Y, Doi T, Kuriyama $\mathrm{H}$, Miller JM, Yamashita T: Intra-cochlear administration of dexamethasone attenuates aminoglycoside ototoxicity in the guinea pig. Hear Res 2002;167:61-70.

Kim HJ, Oh GS, Lee JH, Lyu AR, Ji HM, Lee SH, Song J, Park SJ, You YO, Sul JD, Park C, Chung SY, Moon SK, Lim DJ, So HS, Park R: Cisplatin ototoxicity involves cytokines and STAT6 signaling network. Cell Res 2011;21: 944-956.

Korver KD, Rybak LP, Whitworth C, Campbell $\mathrm{KM}$ : Round window application of D-methionine provides complete cisplatin otoprotection. Otolaryngol Head Neck Surg 2002;126: 683-689.

Lambert PR, Nguyen S, Maxwell KS, Tucci DL, Lustig LR, Fletcher M, Bear M, Lebel C: A randomized, double-blind, placebo-controlled clinical study to assess safety and clinical activity of OTO-104 given as a single intratympanic injection in patients with unilateral Ménière's disease. Otol Neurotol 2012;33:12571265.

Marshak T, Steiner M, Kaminer M, Levy L, Shupak A: Prevention of cisplatin-induced hearing loss by intratympanic dexamethasone: a randomized controlled study. Otolaryngol Head Neck Surg 2014;150:983-990.

Murphy D, Daniel SJ: Intratympanic dexamethasone to prevent cisplatin ototoxicity: a guinea pig model. Otolaryngol Head Neck Surg 2011; 145:452-457.

Nakai Y, Konishi K, Chang KC, Ohashi K, Morisaki N, Minowa Y, Morimoto A: Ototoxicity of the anticancer drug cisplatin. An experimental study. Acta Otolaryngol 1982;93:227232.

Paksoy M, Ayduran E, Sanli A, Eken M, Aydin S, Oktay ZA: The protective effects of intratympanic dexamethasone and vitamin E on cisplatin-induced ototoxicity are demonstrated in rats. Med Oncol 2011;28:615-621.

-Piu F, Wang X, Fernandez R, Dellamary L, Harrop A, Ye Q, Sweet J, Tapp R, Dolan DF, Altschuler RA, Lichter J, LeBel C: OTO-104: a sustained-release dexamethasone hydrogel for the treatment of otic disorders. Otol Neurotol 2011;32:171-179.

Rarey KE, Curtis LM: Receptors for glucocorticoids in the human inner ear. Otolaryngol Head Neck Surg 1996;115:38-41.
Rybak LP: Mechanisms of cisplatin ototoxicity and progress in otoprotection. Curr Opin Otolaryngol Head Neck Surg 2007;15:364369.

Rybak LP, Whitworth CA, Mukherjea D, Ramkumar V: Mechanisms of cisplatin-induced ototoxicity and prevention. Hear Res 2007;226: 157-167.

Rybak LP, Whitworth CA, Somani S: Application of antioxidants and other agents to prevent cisplatin ototoxicity. Laryngoscope 1999;109: 1740-1744.

Saito T, Aran JM: Comparative ototoxicity of cisplatin during acute and chronic treatment. ORL J Otorhinolaryngol Relat Spec 1994;56: 315-320.

ten Cate WJ, Curtis LM, Small GM, Rarey KE: Localization of glucocorticoid receptors and glucocorticoid receptor $\mathrm{mRNAs}$ in the rat cochlea. Laryngoscope 1993;103:865-871.

Van De Water TR, Dinh CT, Vivero R, Hoosien G, Eshraghi AA, Balkany TJ: Mechanisms of hearing loss from trauma and inflammation: otoprotective therapies from the laboratory to the clinic. Acta Otolaryngol 2010;130:308311 .

Wang J, Ladrech S, Pujol R, Brabet P, Van De Water TR, Puel JL: Caspase inhibitors, but not c-Jun $\mathrm{NH}_{2}$-terminal kinase inhibitor treatment, prevent cisplatin-induced hearing loss. Cancer Res 2004;64:9217-9224.

-Wang X, Dellamary L, Fernandez R, Harrop A, Keithley EM, Harris JP, Ye Q, Lichter J, Lebel C, Piu F: Dose-dependent sustained release of dexamethasone in inner ear cochlear fluids using a novel local delivery approach. Audiol Neurootol 2009; 14:393-401.

Wang X, Dellamary L, Fernandez R, Ye Q, Lebel C, Piu F: Principles of inner ear sustained release following intratympanic administration. Laryngoscope 2011a;121:385-391.

Wang X, Fernandez R, Dellamary L, Harrop A, Ye Q, Lichter J, Lau D, Lebel C, Piu F: Pharmacokinetics of dexamethasone solution following intratympanic injection in guinea pig and sheep. Audiol Neurootol 2011b;16:233-241.

Wimmer C, Mees K, Stumpf P, Welsch U, Reichel $\mathrm{O}$, Suckfull M: Round window application of D-methionine, sodium thiosulfate, brain-derived neurotrophic factor, and fibroblast growth factor-2 in cisplatin-induced ototoxicity. Otol Neurotol 2004;25:33-40. 


\section{Editor's Note}

\section{Audiology}

Neurotology
The editorial staff wishes to state that when reviewing the following two papers in this issue [Audiol Neurotol 2016;21:12-21 and 2016;21:22-29], the two editors Dr. Harris and Dr. Ryan, who have an equity interest in Otonomy Inc., had no involvement in the review process in order to prevent any conflict of interest. 